Check for updates

Cite this: RSC Adv., 2017, 7, 23444

Received 2nd April 2017

Accepted 24th April 2017

DOI: $10.1039 / c 7 r a 03784 h$

rsc.li/rsc-advances

\section{Ultrasonic-template technology inducing and regulating cationic microblocks in CPAM: characterization, mechanism and sludge flocculation performance $\dagger$}

\begin{abstract}
Li Feng, (D) abc Huaili Zheng, ${ }^{\text {*abc }}$ Yili Wang, ${ }^{d}$ Shixin Zhang ${ }^{\mathrm{abc}}$ and Bincheng $\mathrm{Xu}^{\mathrm{abc}}$
In this study, the ultrasonic-template polymerization technique (UTPT) was used to generate and regulate the distribution of cationic microblocks in a polymer. The ultrasonic-template copolymer (TPAD-U) of acrylamide (AM) and methacryloxyethyl trimethyl ammonium chloride (DMC) with a novel cationic microblock structure was successfully synthesized through UTPT using sodium polymethacrylate (PMAA) as the template. Fourier transform infrared spectroscopy (FT-IR), ${ }^{1} \mathrm{H}\left({ }^{13} \mathrm{C}\right)$ nuclear magnetic resonance spectroscopy $\left({ }^{1} \mathrm{H}\left({ }^{13} \mathrm{C}\right) \mathrm{NMR}\right)$, scanning electron microscopy (SEM) and thermogravimetric analysis (TGA) were employed to characterize the properties of the polymers. The results showed that evident cationic microblocks formed in TPAD-U. Moreover, the template polymerization mechanism and reaction kinetics were analyzed, and the results showed that the I (ZIP) mechanism and free radical termination were assigned to template copolymerization. The I (ZIP) template mechanism convincingly indicated the formation of the cationic microblocks. The sludge dewatering results demonstrated that TPAD- $U$ showed a better sludge flocculation performance than flocculants prepared by the non-template polymerization technique. During the sludge flocculation process, the cationic microblocks in TPAD-U greatly enhanced the effects of charge neutralization and bridging, which contributed much to a prominent flocculation performance.
\end{abstract}

\section{Introduction}

As a result of the accelerating rate of urbanization and massive increase in human population size during the past few decades, a large amount of domestic sewage wastewater was produced, which posed a serious threat to the aquatic environment. ${ }^{\mathbf{1 - 4}}$ In order to meet the requirements of the current environmental legislation and more stringent disposal regulations, sewage wastewater was treated by the activated sludge process in which huge volumes of excess sludge were generated. ${ }^{5-8}$ In China, the present annual sludge production has reached almost $3 \times 10^{7}$ tons with a high moisture content of approximately $80 \%$. $^{9}$

${ }^{a}$ Key Laboratory of the Three Gorges Reservoir Region's Eco-Environment, Ministry of Education, Chongqing University, Chongqing 400045, China. E-mail: zhl6512@126. com; Fax: +86 23 65120827; Tel: +86 2365120827

${ }^{b}$ National Centre for International Research of Low-carbon and Green Buildings, Chongqing University, Chongqing 400045, China

${ }^{\circ}$ Chongqing Engineering Research Center of Water Treatment Coagulant, Chongqing 400045, China

${ }^{d}$ College of Environmental Science and Engineering, Research Center for Water Pollution Source Control and Eco-remediation, Beijing Forestry University, Beijing 100083, China

$\dagger$ Electronic supplementary information (ESI) available. See DOI: $10.1039 / \mathrm{c} 7 \mathrm{ra0} 3784 \mathrm{~h}$
Therefore, sludge dewatering is of paramount importance in the process of sludge treatment prior to disposal as it reduces the sludge volume and, consequently, affects the subsequent treatment and disposal operations. ${ }^{\mathbf{1 0}}$ However, high water content, presence of organic components which are mainly bacterial cells and extracellular polymeric substances (EPS), colloidal and supracolloidal range particles in the sewage sludge and biological gel structure properties of sludge lead to difficulties in dewatering even at high pressure. ${ }^{11,12}$ Nevertheless, sludge dewatering remained the most expensive and most poorly understood wastewater treatment process. ${ }^{13}$

At present, cationic polyacrylamide (CPAM) has obtained more and more attention because the positive charged CPAM showed a high efficiency in the sludge colloids destabilization through charge neutralization, and the destabilized sludge colloids subsequently agglomerated to form large flocs under the effect of bridging, hence the large flocs could be more easily separated from the water. ${ }^{14,15}$ Meanwhile, various methods have been used to enhance the efficiency of CPAM in sludge dewatering, including using different composite methods, changing different monomers and adding hydrophobic monomers. ${ }^{16,17}$ However, the deficiency remains, for example, the disordered distribution of cationic microblocks in the polymer lead to the weakening of charge neutralization 
ability and the corresponding bridging ability. ${ }^{18}$ The random distribution of cationic monomers can not maximize the whole function and efficiency in charge neutralization and bridging. By contrast, if the flocculant is characterized with the cationic microblocks, more cationic microblocks will be used effectively to increase the ability of charge neutralization and further enhance the ability of bridging. ${ }^{19}$ As a result, the sludge dewatering performance is effectively improved. Thus, a new method should be proposed to control the distribution of cationic units.

Fortunately, the template polymerization technology can be employed to synthesize the flocculant with microblock structures in the study of CPAM. ${ }^{20}$ The ability of charge neutralization can be improved by the novel cationic microblock structures because flocculants with these novel structures are more efficient in neutralizing counterions, which can promote flocculation and improve the flocculation efficiency. ${ }^{18}$ Ultrasonic technology is no doubt recognized as one part of the emerging science and technology. Due to its easy operation, high efficiency, and environmental-friendly rapid processing, it is applied extensively in synthesis of materials, ${ }^{21,22}$ disinfection, ${ }^{23}$ and wastewater treatment. ${ }^{24}$ High shear forces generated by acoustic cavitation can result in homogeneous distribution in aqueous solution, ${ }^{25}$ so it may be applied to distribute and assemble cationic microblocks during the process of template polymerization. It was reported that ultrasonic-template technique has been employed to synthesize novel nanoparticles. ${ }^{26}$ Therefore, ultrasonic-template polymerization technique shown in ESI Fig. S1 $\uparrow$ is proposed to synthesize CPAM with the novel cationic microblocks, and it is beneficial for overcoming the problems associated with traditional template technology. The polymer prepared by copolymerization of methacryloxyethyl trimethyl ammonium chloride (DMC) and acrylamide (AM) is named as CPAD which is regarded as one important and widely used flocculant in the family of CPAM. It will be more significant to design a CPAD with an evident cationic microblock structure through ultrasonic-template polymerization technique (UTPT), and this new method will give an insight into the domain of polymer science and the similar.

In this study, the ultrasonic-template technology was used to prepare TPAD-U with a cationic microblock structure and a rough surface morphology. In order to study the effect of ultrasonic-template polymerization technique on the structural characters of the products, many kinds of advanced analysis were used, including Fourier transform infrared spectroscopy (FT-IR), ${ }^{1} \mathrm{H}\left({ }^{13} \mathrm{C}\right)$ nuclear magnetic resonance spectroscopy $\left({ }^{1} \mathrm{H}\left({ }^{13} \mathrm{C}\right) \mathrm{NMR}\right)$, scanning electron microscopy (SEM) and thermogravimetric analysis (TGA). Besides, the ultrasonic-template polymerization mechanism was investigated though the reaction kinetics and association constant $\left(K_{\mathrm{M}}\right)$. At last, the polymers were used to make a comparison to observe the impact of cationic microblocks on sludge flocculation, and the sludge flocculation performance was expressed by filter cake moisture content (FCMC), specific resistance to filtration (SRF), residual turbidity (RT), floc size and floc morphology.

\section{Materials and methods}

\subsection{Materials}

Reagents used in this experiment were of analytical grade except AM, DMC, and template sodium polymethacrylate (PMAA) which were of technical grade. The monomer AM was provided by Chongqing Lanjie Tap Water Company (Chongqing, China). DMC (78 wt $\%$ in water) and urea $\left[\mathrm{CO}\left(\mathrm{NH}_{2}\right)_{2}\right]$ were purchased from Guangchuangjing Import and Export Co., Ltd. (Shanghai, China). The sodium polymethacrylate (PMAA) was obtained from Shandong Xintai Water Treatment (Zaozhuang, China) and its molecular weight is 5100. Initiator 2,2'-azobis [2-(2imidazolin-2-yl)propane] dihydrochloride (VA-044) was purchased from Apotheker Chemical Reagent Co., Ltd. (Chendou, China). Deionized water was used throughout the experiment. Commercial flocculants CPAM-1 (copolymerization of AM and acryloyloxyethyl trimethyl ammonium chloride (DAC)) and CPAM-2 (copolymerization of AM and dimethyldiallyl ammonium chloride (DMDAAC)) were used for comparison in flocculation test, and their intrinsic viscosities were all of $9.25 \mathrm{dL} \mathrm{g}^{-1}$.

\subsection{Preparation of copolymers}

The ultrasonic-template polymerization technique was employed to synthesize the template copolymer TPAD-U. A certain amount of AM, DMC, urea, PMAA and deionized water was added in $100 \mathrm{~mL}$ quartz jar. The molar ratio of PMAA and DMC kept $1: 1$. Then, the $\mathrm{pH}$ of the reaction solution was adjusted to 4 by $0.5 \mathrm{~mol} \mathrm{~L}^{-1} \mathrm{HCl}$ or $\mathrm{NaOH}$. An ultrasonicator with a frequency of $45 \mathrm{kHz}$ (KQ 2200E, Kunshan ultrasonic instrument Co., LTD, China) was used as an ultrasonic source. In order to form a homogeneous solution, the mixture was

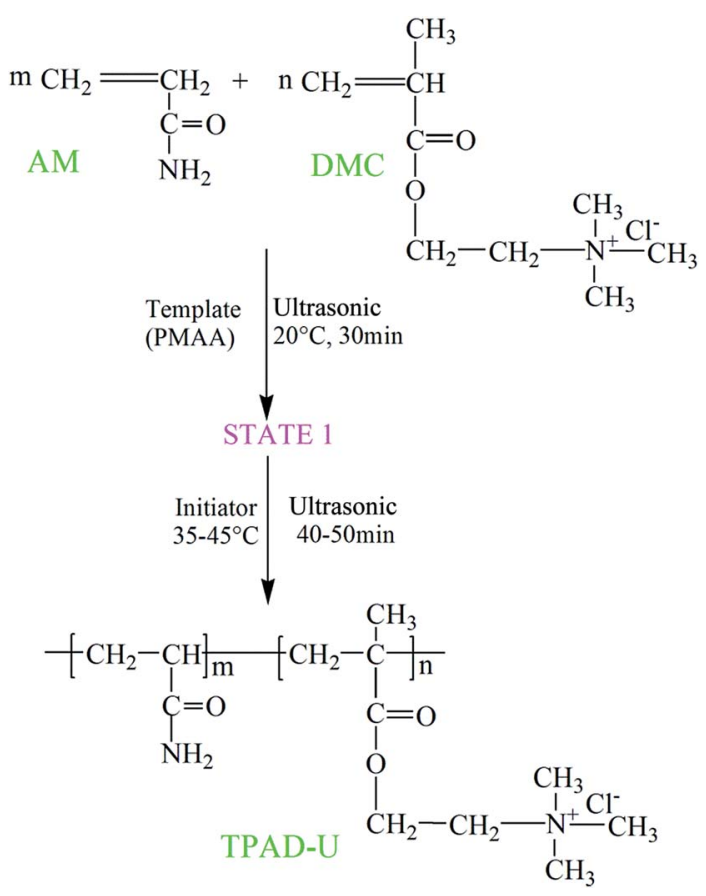

Fig. 1 The proposed reaction route for synthesis of TPAD-U. 
sonicated at $45 \mathrm{kHz}$ and $20{ }^{\circ} \mathrm{C}$ for $30 \mathrm{~min}$. Subsequently, the purified nitrogen was bubbled into the aqueous solution at low temperature for about $30 \mathrm{~min}$ to remove the oxygen. The quartz jar was sealed immediately after addition of a predetermined dose of initiator VA0-44 to the mixture, and then continuously sonicated at $35-45{ }^{\circ} \mathrm{C}$ for $40-50 \mathrm{~min}$. When the reaction was over, the copolymer was aged for $2 \mathrm{~h}$ at room temperature to increase the polymerization degree. The copolymer was dissolved in water, and the $\mathrm{pH}$ was adjusted to a value of less than 2 and then purified by acetone and ethanol. Finally, the flocculant was dried in a vacuum oven at $60^{\circ} \mathrm{C}$. The preparation of CPAD was similar to that of TPAD-U except that no ultrasonic and template was used. Besides, the polyacrylamide (PAM) prepared in laboratory was used for contrastive analysis of characterization. The proposed reaction route for TPAD-U was outlined in Fig. 1.

\subsection{Characteristics of copolymers}

The FT-IR spectra of the products were recorded using $\mathrm{KBr}$ pellets on a 550 Series II infrared spectrometer (Mettler Toledo Instruments Co., Ltd., Switzerland) in the range between 500 and $4000 \mathrm{~cm}^{-1}$. The ${ }^{1} \mathrm{H}\left({ }^{13} \mathrm{C}\right)$ NMR of copolymers were obtained in $\mathrm{D}_{2} \mathrm{O}$ with an Avance 500 nuclear magnetic resonance spectrometer (Bruker Company, Ettlingen, Germany). Meanwhile, the SEM analysis was conducted on MIRA 3 LMU SEM system (TES-CAN Company, Czech Republic). Thermogravimetric (TGA) and differential scanning calorimetry (DSC) were carried out at a heating rate of $10{ }^{\circ} \mathrm{C} \mathrm{min}{ }^{-1}$ under a nitrogen flow of 20 $\mathrm{mL} \min ^{-1}$ from 20 to $600{ }^{\circ} \mathrm{C}$ on a DTG-60H synchronal thermal analyzer (Shimadzu, Kyoto, Japan).

\subsection{Determination of $K_{M}$ and reaction kinetics}

The ultrasonic-initiated template polymerization mechanism was discussed and determined through the investigation of association constant $\left(K_{\mathrm{M}}\right)$ and reaction kinetics. The association constant $\left(K_{\mathrm{M}}\right)$ between DMC and PMAA and the polymerization rate $\left(R_{\mathrm{p}}\right)$ were examined through bag filter method and dilatometer method, respectively. ${ }^{27,28}$ The details about the two methods were listed in ESI Text $\mathrm{S} 1 . \dagger$

\subsection{Dewatering experiment}

In this study, the polymers used for structure properties characterization and flocculation tests were displayed in Table 1. Raw sludge used in this experiment was collected from Jiguanshi Wastewater Treatment Plant (Chongqing, China) with a cyclic-activated sludge system. The sludge collected from this plant was characterized by a moisture content of $97.9 \%$, a mass density of $0.997 \mathrm{~kg} \mathrm{~L}^{-1}$, a zeta potential of $-22.3 \mathrm{mV}$, a VSS/TSS of 0.75 , and an initial sludge $\mathrm{pH}$ value of 7.2 . The sludge dewatering experiments could be conducted on a buchner funnel or a Jar-test apparatus, and in this study, a program-controlled Jartest apparatus (ZR4-6, Zhongrun Water Industry Technology Development Co. Ltd., China) was used to proceed the sludge dewatering experiments at room temperature. The sludge flocculation performance of the flocculants was expressed in terms of FCMC, RT and floc properties. Each measurement was
Table 1 The details of flocculants used in the characterization and flocculation tests

\begin{tabular}{lllll}
\hline Flocculants $^{a}$ & $\begin{array}{l}\text { Cationic } \\
\text { degree }\end{array}$ & $\begin{array}{l}\text { Intrinsic viscosity } \\
\left(\mathrm{dL} \mathrm{g}^{-1}\right)\end{array}$ & $\begin{array}{l}\text { Conversion } \\
\text { rate }(\%)\end{array}$ & $\begin{array}{l}\text { Synthetic } \\
\text { method }\end{array}$ \\
\hline TPAD-U & 30.0 & 9.19 & 99.7 & UTPT \\
CPAD & 30.0 & 9.23 & 99.5 & N-UTPT \\
PAM & - & 9.25 & 99.9 & N-UTPT \\
CPAM-1 & 30.0 & 9.25 & - & - \\
CPAM-2 & 30.0 & 9.25 & - & -
\end{tabular}

${ }^{a}$ TPAD-U: copolymer of DMC and AM by ultrasonic-template technique (UTPT); CPAD: copolymer of DMC and AM by non ultrasonic-template technique (N-UTPT); PAM: homopolymer of AM by N-UTPT; CPAM-1: commercial copolymer of DAC and AM; CPAM-2: commercial copolymer of DMDAAC and AM.

performed in triplicate and the final results were the average of three runs. In sludge dewatering experiments, a certain amount of flocculant was added to $500 \mathrm{~mL}$ sludge in a glass beaker. The sludge was rapid stirred at $200 \mathrm{rpm}$ for $30 \mathrm{~s}$, followed by a slow stirring at $50 \mathrm{rpm}$ for $10 \mathrm{~min} .{ }^{29}$ Flocs formed and settled for $30 \mathrm{~min}$. The zeta potential of the supernatant and the turbidity of the supernatant collected from $2 \mathrm{~cm}$ under the surface were conducted on a Zetasizer Nano ZS90 (Malvern Instruments Ltd., Malvern, UK) and a 2100P turbidity meter (HACH, Loveland, $\mathrm{CO})$, respectively. After a rapid agitation, the floc size was measured by a laser diffraction instrument (Mastersizer 2000, Malvern, U.K.). The filterability of the sludge was measured by FCMC and SRF which were illustrated in ESI Text S2. $\dagger$ Besides, a camera (Millet five, China) was used to observe the flocs morphology of conditioned sludge.

\section{Results and discussion}

\subsection{The association constant $\left(K_{M}\right)$ and template polymerization mechanism}

The $K_{\mathrm{M}}$ played an important role in the template copolymer system because the adhesion strength between cationic monomer and template could be intuitively reflected from $K_{\mathrm{M}}$, and thus the type and mechanism of template copolymerization could be determined. In this study, a $K_{\mathrm{M}}$ value of 12.26 was obtained at $n_{\mathrm{DMC}}: n_{\mathrm{PMAA}}=1$, which indicated that approximately three quarters of the DMC was pre-absorbed and anchored on the polymer molecular chain of template PMAA to form precursor of microblock structure under the electrostatic force, and the precursor was homopolymerized by ultrasonicinitiated radiation to breed a microblock segment. Thus, the template polymerization mechanism ultrasonic-initiated belonged to (I) ZIP mechanism rather than (II) pick-up exhibited in Fig. $2 .^{30}$ Besides, it provided a powerful support for the formation of the cationic microblock structure in TPAD-U.

\subsection{Reaction kinetics}

3.2.1. Effect of pH. Fig. 3(a) and (b) displayed the impact of $\mathrm{pH}$ on conversion and $R_{\mathrm{p}}$ at $n_{\mathrm{DMC}}: n_{\mathrm{PMAA}}=1: 1, n_{\mathrm{DMC}}: n_{\mathrm{AM}}=$ $1: 3$, total monomer concentration $\left(C_{\mathrm{M}}\right)=4.0 \mathrm{~mol} \mathrm{~L}^{-1}$ and 


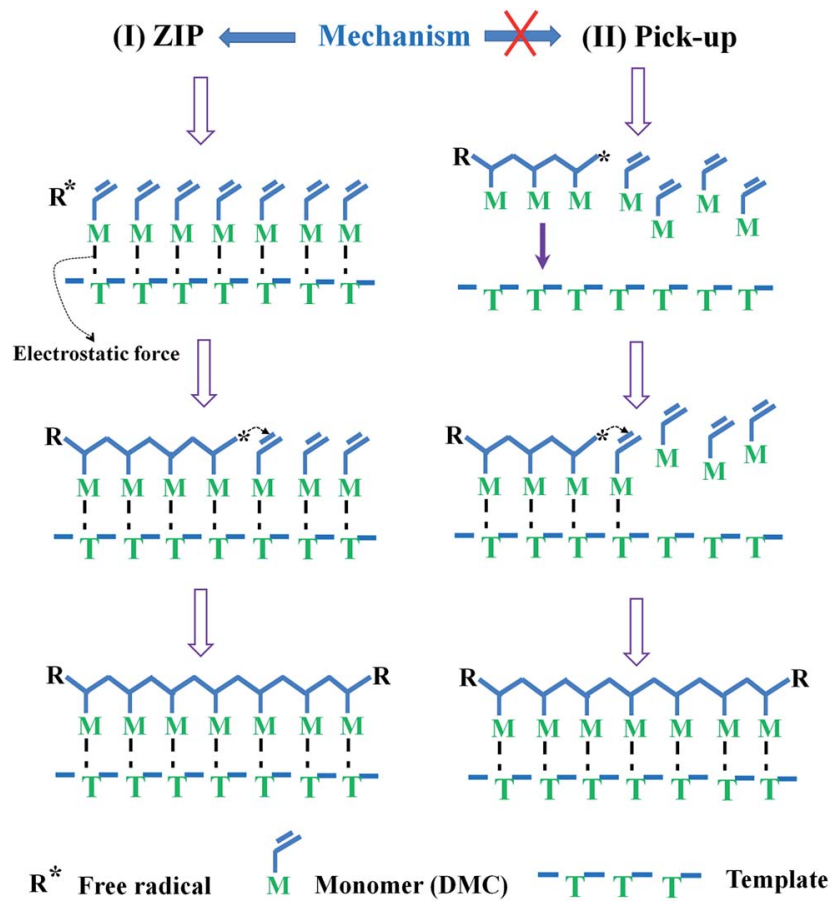

Fig. 2 The mechanism of template copolymerization.

initiator concentration $\left(C_{\mathrm{I}}\right)=8.0 \times 10^{-4} \mathrm{~mol} \mathrm{~L}^{-1}$. It was clear that both conversion and $R_{\mathrm{p}}$ initially increased from $\mathrm{pH}=2$ to $\mathrm{pH}=4$ and reached their respective topic value at $\mathrm{pH}=4$, and then declined rapidly with the increasing of $\mathrm{pH}$ form 4 to 10 . The low $\mathrm{pH}$ value resulted in imidization reaction of $\mathrm{AM}$ and a decrease of template dissociation degree, thus weakening the template effect. Meanwhile, when the $\mathrm{pH}$ value was too high, the hydroxyl methylation reaction occurred, which was adverse to template copolymerization. Therefore, the optimal range of $\mathrm{pH}$ was from 4 to 6 .

3.2.2. Effect of total monomer concentration $\left(C_{M}\right)$. As shown in Fig. 3(c) and (d), the effect of $C_{\mathrm{M}}$ on conversion and $R_{\mathrm{p}}$ was investigated at $n_{\mathrm{DMC}}: n_{\mathrm{PMAA}}=1: 1, n_{\mathrm{DMC}}: n_{\mathrm{AM}}=1: 3, \mathrm{pH}$ $=4$ and initiator concentration $\left(C_{\mathrm{I}}\right)=8.0 \times 10^{-4} \mathrm{~mol} \mathrm{~L}^{-1}$. Obviously, the conversion and $R_{\mathrm{p}}$ were positively associated with the $C_{\mathrm{M}}$, and the higher the $C_{\mathrm{M}}$ was, the larger the value of conversion and $R_{\mathrm{p}}$ became. In Fig. 3(d), the slop of the fitting straight line was 1.698, which meant that a relationship of $R_{\mathrm{p}} \propto$ $\mathrm{C}_{\mathrm{M}}^{1.698}$ was between $C_{\mathrm{M}}$ and $R_{\mathrm{p}}$. The power value (1.698) of $C_{\mathrm{M}}$ was more than 1 , this phenomenon was caused by the product precipitation in the copolymerization process, and it was common in free radical polymerization reaction. ${ }^{31}$

3.2.3. Effect of mole ratio of PMAA to DMC. In this part, the effect of mole ratio of PMAA to DMC on conversion and $R_{\mathrm{p}}$ was examined, and the results was illustrated in Fig. 3(e) and (f). The reaction conditions were set at $n_{\mathrm{DMC}}: n_{\mathrm{AM}}=1: 3, \mathrm{pH}=4$, total monomer concentration $\left(C_{\mathrm{M}}\right)=4.0 \mathrm{~mol} \mathrm{~L}^{-1}$ and initiator concentration $\left(C_{\mathrm{I}}\right)=8.0 \times 10^{-4} \mathrm{~mol} \mathrm{~L}^{-1}$. With the increase of mole ratio of PMAA to DMC from $0.25: 1$ to $1: 1$, the value of conversion and $R_{\mathrm{p}}$ all reached the maximum, and then displayed a decrease after $n_{\mathrm{PMAA}}: n_{\mathrm{DMC}}>1: 1$. The variation trend of conversion and $R_{\mathrm{p}}$ as a function of $n_{\mathrm{PMAA}}: n_{\mathrm{DMC}}$ was accorded with the typical I (ZIP) template polymerization mechanism..$^{32}$ Significantly, the template PMAA acted as a role of assembling and distributing cationic monomer. The template would be fully filled by DMC at the $n_{\mathrm{PMAA}}: n_{\mathrm{DMC}}<1$, and therefore the conversion and $R_{\mathrm{p}}$ all displayed an increase with the increasing of $n_{\mathrm{PMAA}}: n_{\mathrm{DMC}}$. However, if the $n_{\mathrm{PMAA}}: n_{\mathrm{DMC}}$ was more than $1: 1$, a part of template would be lack of DMC and the continuous distribution of DMC segments was destroyed, and thus leading to the termination of initiation reaction. As a result, the conversion and $R_{\mathrm{p}}$ decreased.

\subsection{Characterization of flocculants}

3.3.1. FTIR spectral analysis. As showed in Fig. 4, the FT-IR spectra of TPAD-U and CPAD were almost the same, but not quite identical. The FT-IR spectra of the two samples displayed the following similar peaks: $-\mathrm{NH}_{2}$ stretching vibration was at $3433 \mathrm{~cm}^{-1}$ in $\mathrm{AM} ;{ }^{33}-\mathrm{CH}_{3}$ and $-\mathrm{CH}_{2}$ - asymmetric stretching vibration was at 2934 and $2840 \mathrm{~cm}^{-1}$, respectively; ${ }^{34} \mathrm{C}=\mathrm{O}$ stretching vibration was at $1662 \mathrm{~cm}^{-1} ;-\mathrm{CH}_{2}$ - bending vibration was at $1452 \mathrm{~cm}^{-1}$ in $-\mathrm{CH}_{2}-\mathrm{N}^{+} ;{ }^{18} \mathrm{C}-\mathrm{O}-$ stretching vibration was at $1161 \mathrm{~cm}^{-1}$ in ester groups; and $-\mathrm{N}^{+}-\left(\mathrm{CH}_{3}\right)_{3}$ bending vibration was at $953 \mathrm{~cm}^{-1}$ in DMC; ${ }^{19}$ the characteristic chemical groups of AM and DMC were all observed in TPAD-U and CPAD, revealing that TPAD-U and CPAD were successfully synthesized through copolymerization of AM and DMC. Meanwhile, it also indicated that the cationic microblock structure almost had no impact on the chemical structure of the functional group in the prepared template copolymer except the slight shift in the peak area. For instance, the peak area of $\mathrm{C}=\mathrm{O}$ at $1662 \mathrm{~cm}^{-1}$ in TPAD-U was larger than that in CPAD.

3.3.2. DSC/TGA analysis. The thermal gravimetric curves of the polymers were shown in Fig. 5. It could be found that both CPAD and TPAD-U displayed three similar stages of the weight loss. In the first stage occurred in the range of $30-185{ }^{\circ} \mathrm{C}$, mass loss was about $14.9 \mathrm{wt} \%$ for CPAD and $11.7 \mathrm{wt} \%$ for TPAD-U, which was associated with the evaporation of moisture in the polymers. ${ }^{35}$ In the second stage occurred in the range of 185$350{ }^{\circ} \mathrm{C}$, mass loss of $32.9 \mathrm{wt} \%$ for CPAD and $25.5 \mathrm{wt} \%$ for TPAD$\mathrm{U}$ were observed, which was due to the imine reaction of the amide group and the thermal decomposition of methyl in the quaternary ammonium groups. ${ }^{36}$ The final stage occurred beyond $350{ }^{\circ} \mathrm{C}$, the mass loss of CPAD was about $38.1 \mathrm{wt} \%$ while that of TPAD-U was about $41.5 \mathrm{wt} \%$, which was attributed to the carbonization of the copolymer. ${ }^{37}$ Furthermore, two evident heat absorption peaks at $343.7^{\circ} \mathrm{C}$ and $395.7^{\circ} \mathrm{C}$ for TPAD-U were observed in the final stage, whereas just a single absorption peak at $372.9{ }^{\circ} \mathrm{C}$ appeared in CPAD. An explanation could be that the number of the absorption peak was related to the microstructure of the polymers. The random distribution of cationic monomer DMC in CPAD could not form microblock structure, thus resulting in a single absorption peak during the thermal gravimetric test. However, the template copolymer could generate evident microblock structure, namely, the DMC microblock structure and AM microblock structure, and thereby two sharper and larger heat absorption peaks were observed. The results were corresponding with the analysis shown in Section 3.1 and previous report. ${ }^{18,19}$ 

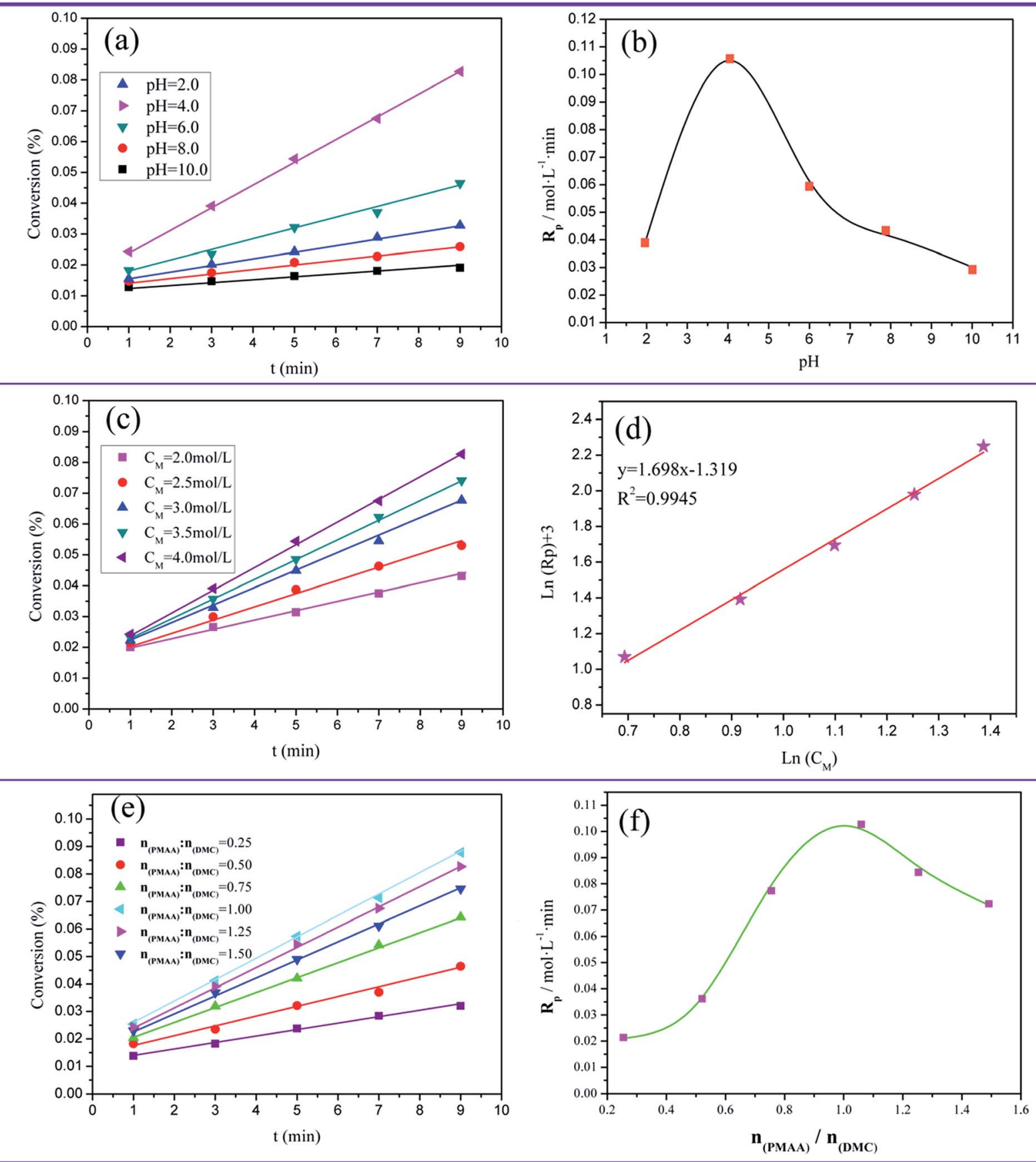

Fig. 3 Effect of $\mathrm{pH}$ on conversion (a) and $R_{\mathrm{p}}$ (b); effect of total monomer concentration $\left(C_{\mathrm{l}}\right)$ on conversion (c) and $R_{\mathrm{p}}(\mathrm{d})$; and effect of $n_{\text {PMAA }}: n_{\text {DMC }}$ on conversion (e) and $R_{\mathrm{p}}(\mathrm{f})$.

3.3.3. ${ }^{1} \mathbf{H}$ NMR spectral analysis. The ${ }^{1} \mathrm{H}$ NMR spectra shown in Fig. 6 further analyzed the microstructure of the PAM, CPAD and TPAD-U. Because the monomer DMC was grafted on the backbone of PAM, the proton chemical environment changed, and thus a slight proton peak shift of $-\mathrm{CH}_{2}-$ (a) at $1.629 \mathrm{ppm}$ and $-\mathrm{CH}-$ (b) at $2.194 \mathrm{ppm}$ were observed in both CPAD and TPAD-U compared with those of PAM. Moreover, CPAD and TPAD-U displayed many similarities, but several subtle differences were very significant to this study. CPAD and TPAD-U showed the following similar characteristic peaks: peak of protons in methyl group $-\mathrm{CH}_{3}$ (c) was at $\delta=1.157 \mathrm{ppm}$ in DMC; peak of protons in the group of $-\mathrm{O}-\mathrm{CH}_{2}-(\mathrm{d})$ was at $\delta=4.49 \mathrm{ppm}$; peak of protons in the methylene group of $\left(-\mathrm{CH}_{2}-\mathrm{N}^{+}\right)(\mathrm{e})$ was at $\delta=3.77 \mathrm{ppm}$ in DMC; the sharp peak of protons in the three equivalent methyl groups of $-\mathrm{N}^{+}\left(\mathrm{CH}_{3}\right)_{3}(\mathrm{f})$ was at $\delta=3.209 \mathrm{ppm}$ in DMC; and the sharp peak of protons in solvent $\mathrm{D}_{2} \mathrm{O}$ was at $\delta=$ $4.79 \mathrm{ppm}$. These results indicated that CPAD and TPAD-U were successfully synthesized by AM and DMC. ${ }^{38}$ Compared with TPAD-U, four weak peaks were observed in the ${ }^{1} \mathrm{H}$ NMR spectra of CPAD. These weak peaks were at $\delta=3.19 \mathrm{ppm}, \delta=3.44 \mathrm{ppm}, \delta=$ 


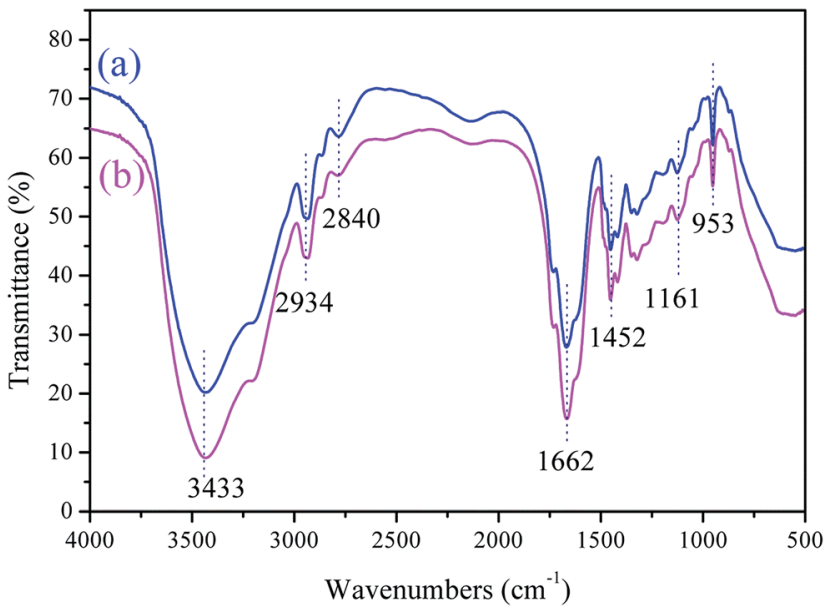

Fig. 4 FT-IR spectra of (a) CPAD and (b) TPAD-U.

$3.65 \mathrm{ppm}$ and $\delta=4.11 \mathrm{ppm}$, respectively. However, those weak peaks did not show up in the ${ }^{1} \mathrm{H}$ NMR spectra of TPAD-U. Although CPAD was the copolymerization of AM and DMC, the distribution of monomer DMC was disordered and uncontrollable. Due to the cationic microblock structure in TPAD-U, the steric conformation and the chemical environment for each group of $-\mathrm{CH}_{2}-\mathrm{N}^{+}$(e), $-\mathrm{O}-\mathrm{CH}_{2}-$ (d), and $-\mathrm{N}^{+}\left(\mathrm{CH}_{3}\right)_{3}$ (f) become identical, and the protons of each group were identical in principle. ${ }^{19,39}$ Therefore, just only one resonance was observed for each group in TPAD-U rather than two or more extra weak peaks in CPAD. The result of ${ }^{1} \mathrm{H}$ NMR spectra was demonstration that the microblock structures formed in TPAD-U.

3.3.4. ${ }^{13} \mathrm{C}$ NMR spectral analysis. Parallel to the ${ }^{1} \mathrm{H}$ NMR spectral, the ${ }^{13} \mathrm{C}$ NMR spectra of TPAD-U, CPAD and PAM were represented in Fig. 7 to further characterize their properties. The peaks at $\delta=34.7 \mathrm{ppm}$ and $\delta=42.1 \mathrm{ppm}$ were attributed to the carbon resonances of methane $\left(\mathrm{CH}_{2}^{-}\right)$(a) and methylene $(-\mathrm{CH}-)(\mathrm{b})$ in TPAD-U, CPAD and PAM. Compared with the ${ }^{13} \mathrm{C}$ NMR spectra of PAM, the characteristic peaks $\left({ }^{13} \mathrm{C}_{\mathrm{c}}{ }^{-13} \mathrm{C}_{\mathrm{I}}\right)$ of TPAD-U and CPAD were all observed at $\delta=17.9 \mathrm{ppm}$, $\delta=45.1 \mathrm{ppm}, \delta=179.7 \mathrm{ppm}, \delta=176.0 \mathrm{ppm}, \delta=58.9 \mathrm{ppm}, \delta=$
$64.8 \mathrm{ppm}, \delta=53.5 \mathrm{ppm}$, respectively. The above results further demonstrated that the copolymers of TPAD-U and CPAD successfully synthesized by AM and DMC. Moreover, the proportion of the monomer segment could be calculated by the area of the carbonyl carbon resonance peaks by using MestReNova software, ${ }^{40}$ and the results were displayed in Table 2. The carbonyl carbon resonance peaks shown in the rectangle in Fig. 7 from left to right was from 1 to 6 . If AM unit was abbreviated as A and DMC unit was abbreviated as D, the peaks of 1, 2 and 3 were represent AAA, AAD, DAD segments with A as the central, and 4, 5 and 6 were represent ADA, DDA, DDD segments with $\mathrm{D}$ as the central. Obviously, the microblock structures had an evident influence on the mole fraction of the triad sequence. Because of these microblocks in TPAD-U, the length of DDD and AAA became longer than those in TPAD without microblock structures. For example, the mole fractions of the AAA and DDD triad sequence in TPAD-U were $10.7 \%$ and $21.8 \%$, respectively, whereas those in CPAD were $8.9 \%$ and $13.5 \%$. Based on the above ${ }^{13} \mathrm{C}$ NMR analytical results, it could be concluded that the evident DMC microblock structure was successfully prepared in TPAD-U rather than CPAD, which was in consistent with the analytical results of DSC/TGA and ${ }^{1} \mathrm{H}$ NMR spectral.

3.3.5. SEM of polymers. The SEM images of the polymers (PAM, CPAD and TPAD-U) were displayed in Fig. 8 to investigated their amorphous morphology. It was more clear that there kind of polymers presented different surface morphology. As a homopolymer of AM, PAM showed a smooth and regular surface morphology. ${ }^{41}$ However, with the grafting of DMC on AM, profound morphological change occurred. The introduction of DMC to AM chain destroyed the originally structure of $\mathrm{AM}$, and thereby resulting in a porous structure with a rough surface area, which could be confirmed by fractal dimension. The linear correlation of the logarithm of projected area $(A)$ and the characteristic length $(L)$ was observed, and the average fractal dimensions could be calculated by using Image-Pro Plus 6.0 software. ${ }^{42}$ The average fractal dimension of the polymers followed the order of PAM $(1.218)<$ CPAD $(1.426)<$ TPAD-U (1.631), which indicated that the surface of TPAD-U and CPAD was more rough and irregular than PAM. Besides, compared
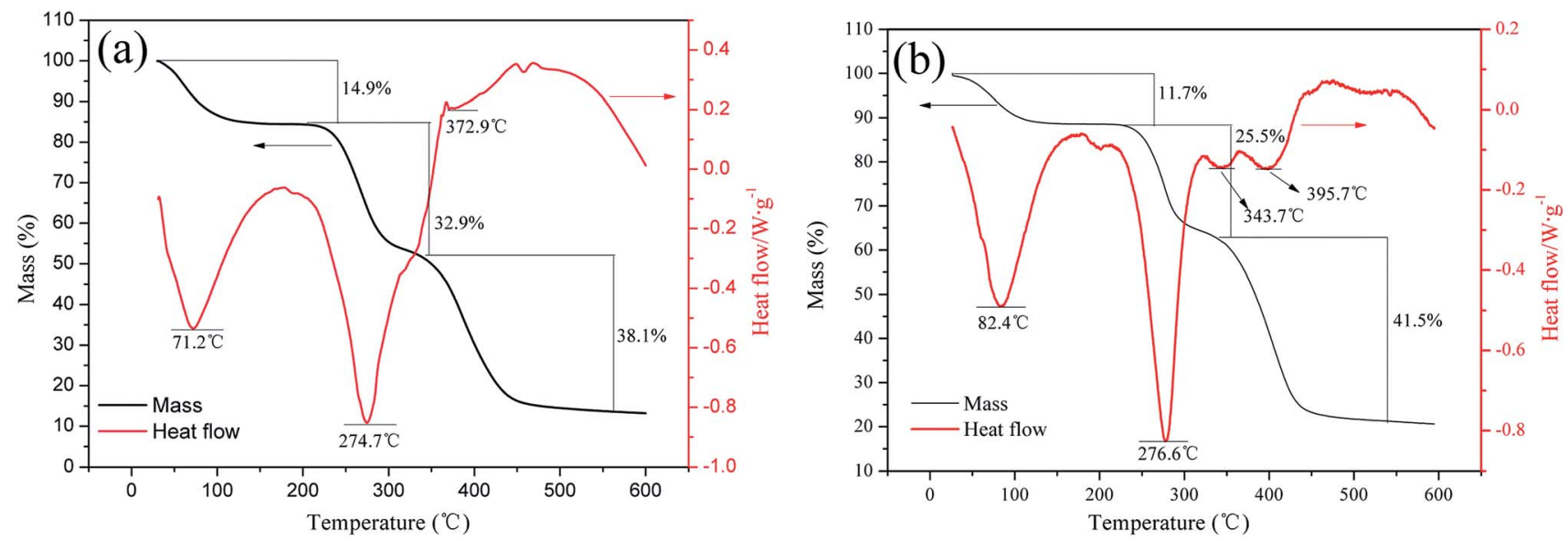

Fig. 5 Thermogravimetric curve of (a) CPAD and (b) TPAD-U. 


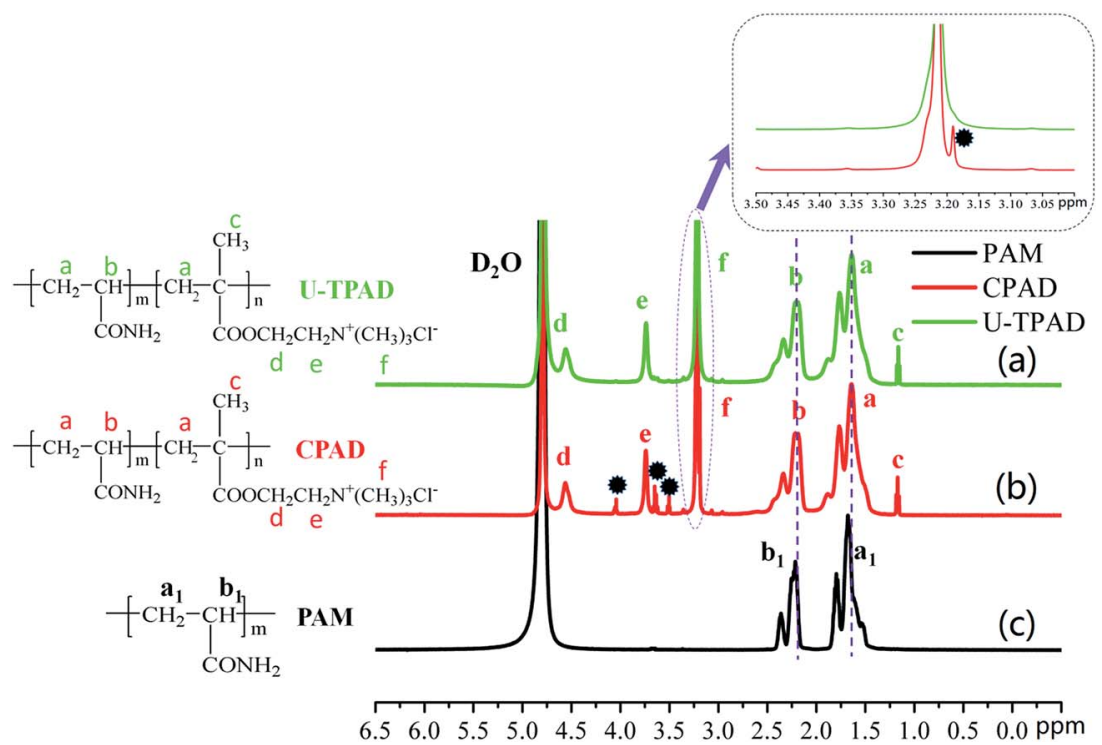

Fig. $6{ }^{1} \mathrm{H}$ NMR spectrum of (a) TPAD-U, (b) CPAD and (c) PAM.

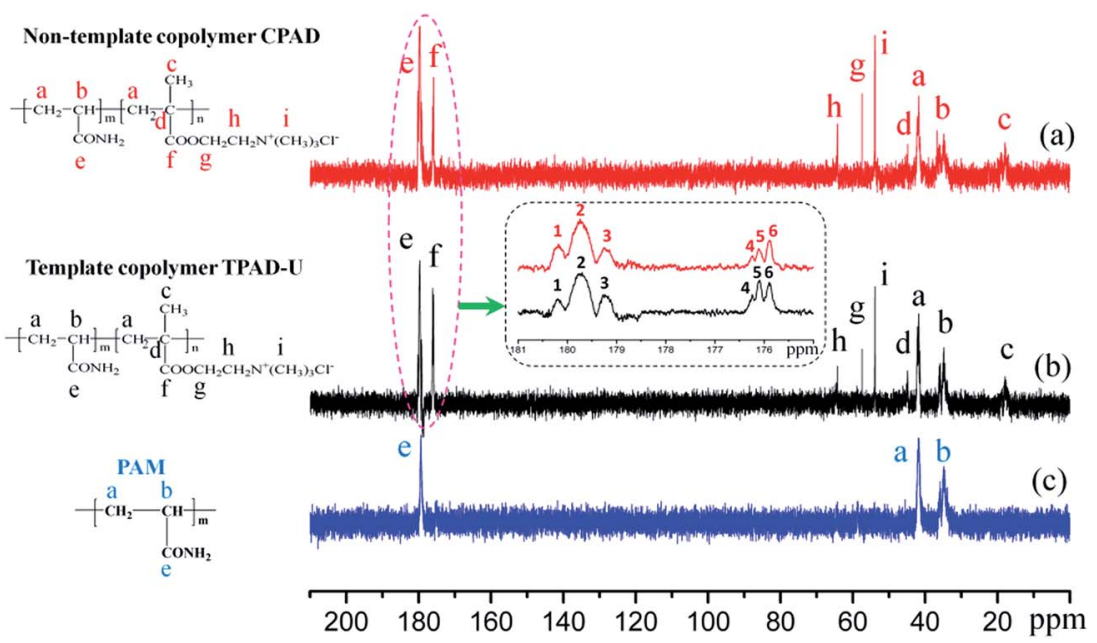

Fig. $7{ }^{13} \mathrm{C}$ NMR spectrum of (a) CPAD, (b) TPAD-U and (c) PAM.

with the CPAD, TPAD-U displayed a more rugged and rough surface morphology which was caused by the microblock structured, and this similar phenomenon has been observed in the template copolymer in previous study. ${ }^{18}$

Table 2 The mole fraction of the triads sequence structure using MestReNova software

\begin{tabular}{lllllll}
\hline Flocculants $^{a}$ & $\begin{array}{l}\text { F(AAA) } \\
(\%)\end{array}$ & $\begin{array}{l}\text { F(AAD) } \\
(\%)\end{array}$ & $\begin{array}{l}\text { F(DAD) } \\
(\%)\end{array}$ & $\begin{array}{l}\text { F(ADA) } \\
(\%)\end{array}$ & $\begin{array}{l}\text { F(DDA) } \\
(\%)\end{array}$ & $\begin{array}{l}\text { F(DDD) } \\
(\%)\end{array}$ \\
\hline CPAD & 8.9 & 41.3 & 15.7 & 3.2 & 17.4 & 13.5 \\
TPAD-U & 10.7 & 37.9 & 13.4 & 3.1 & 13.1 & 21.8
\end{tabular}

${ }^{a}$ TPAD-U: copolymer of DMC and AM by ultrasonic-template technique (UTPT); CPAD: copolymer of DMC and AM by non ultrasonic-template technique (N-UTPT); A: AM unit; D: DMC unit; F(AAA) to F(DDD): mole fraction of the AAA triad sequence to DDD triad sequence.

\section{Flocculation test}

\subsection{Effect of flocculant dosage on dewatering performance}

Contrast tests were conducted among the four flocculants (TPAD-U, CPAD, CPAM-1 and CPAM-2) to evaluated the effects of cationic microblocks on sludge flocculation performance in terms of SRF, FCMC and RT. The raw sludge had a FCMC of $96.8 \%$ and $\mathrm{SRF}$ of $132.9 \times 10^{12} \mathrm{~m} \mathrm{~kg}^{-1}$. Meanwhile, the zeta potential regarded as an main and extensive index were investigated to analyze the flocculation mechanisms. ${ }^{\mathbf{4 3 , 4 4}}$ As shown in Fig. 9, the FCMC, SRF and RT of the four flocculants initially decreased at a dosage ranging from $10 \mathrm{mg} \mathrm{L}^{-1}$ to $40 \mathrm{mg} \mathrm{L}^{-1}$, and then increased at a dosage ranging from $40 \mathrm{mg} \mathrm{L}^{-1}$ to $90 \mathrm{mg}$ $\mathrm{L}^{-1}$. At low dosage, the flocculants failed to completely neutralized the negative charged sludge particles, thus resulting in a small, loose and fragile flogs. As a result, a high FCMC, SRF 

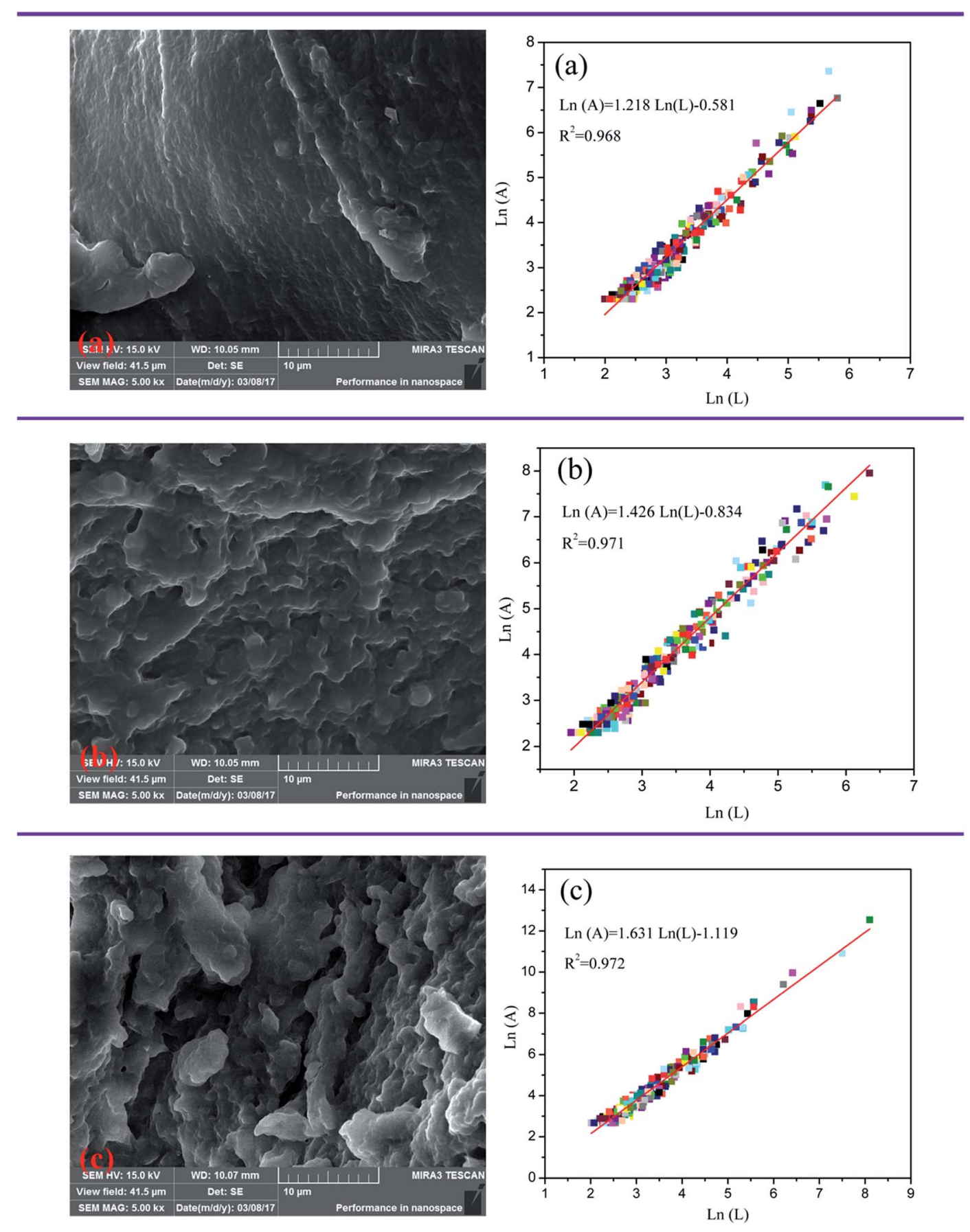

Fig. 8 SEM images of (a) PAM, (b) CPAD and (c) TPAD-U.

and RT was obtained..$^{45}$ However, the overdose would increase the positive charge of the colloidal system and the electronic repulsion would be increased, hence the destabilized particles re-stabilized and the flocculation efficiency was weakened. ${ }^{33,42}$ It was worth noting that, in the full dosage range, TPAD-U showed the most prominent flocculation performance than the other three. When the dosage was at $40 \mathrm{mg} \mathrm{L}^{-1}$, the minimum FCMC of $63.6 \%$, SRF of $4.9 \times 10^{12} \mathrm{~m} \mathrm{~kg}^{-1}$ and RT of $5.2 \mathrm{NTU}$ were acquired for TPAD-U. The phenomenon could be explained as follows. The cationic microblocks in TPAD-U with a high zeta potential could extremely enhance the charge neutralization ability and improve the usage efficiency of DMC, and thus it would reached the isoelectric point at a relative low dosage. In other words, TPAD-U was more capable in charge neutralization and destabilization of sludge colloidal particles than CPAD, CPAM-1 and CPAM-2 at the same dosage. Besides, the optical dosages for the four flocculants were not same with those at the isoelectric point, it indicated that mechanisms such as bridging or patching also worked with the charge neutralization mechanism in the flocculation process. 

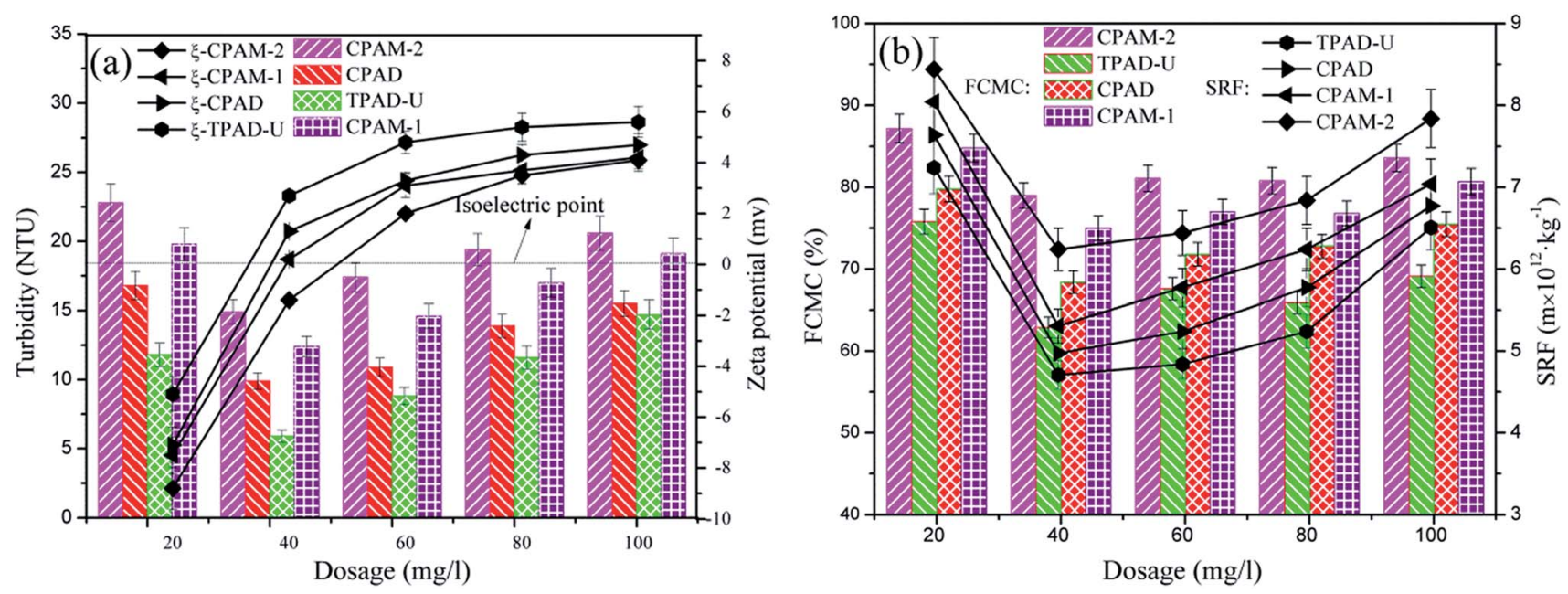

Fig. 9 Effect of dosage on (a) RT and zeta potential, (b) FCMC and SRF.

\subsection{Effect of $\mathbf{p H}$ on sludge dewatering performance}

Previous study has demonstrated that the $\mathrm{pH}$ displayed an important impact on the sludge flocculation performance, and the flocculant surface properties could be changed under different $\mathrm{pH}$ value. ${ }^{46}$ In this section, the influence of $\mathrm{pH}$ on sludge flocculation performance was investigated at the optimum flocculant dosage of $40 \mathrm{mg} \mathrm{L}^{-1}$. Fig. 10 displayed the impact of $\mathrm{pH}$ on the RT, FCMC and SRF, where TPAD-U, CPAD, CPAM-1 and CPAM-2 showed the similar trend of decreasing initially at the $\mathrm{pH}$ range of 1 to 7 and then increasing at the $\mathrm{pH}$ range of 7 to 11 . However, the zeta potential gradually declined at the $\mathrm{pH}$ range of 1 to 11 . The strong acid ( $\mathrm{pH}$ : 2.0-4.0) would lead to excessive hydrogen ions to enhance the positive charge repulsion of polymers, and the strong alkali (pH: 9.0-11.0) would result in sufficient hydroxyl ions instead of negative charged particles to neutralize the positive charge of polymers. ${ }^{47}$ The strong acid and alkali would severely weaken the charge neutralization ability and more colloidal particles would not be neutralized thoroughly, and thus a desirable flocculation performance could not be obtained.
Moreover, TPAD-U showed the minimum value of RT (4.9 NTU), FCMC $(62.4 \%)$ and SRF $\left(4.8 \times 10^{12} \mathrm{~m} \mathrm{~kg}^{-1}\right)$ and the strongest zeta potential among the four flocculants in the full $\mathrm{pH}$ range. It indicated that TPAD-U had the strongest charge neutralization ability generated by the cationic microblocks to possess the most excellent sludge flocculation performance in a broad scope of $\mathrm{pH}$. Besides, the cationic microblocks had a strong electrostatic repulsion between the polymer chains of TPAD-U, which was favorable for the extension and spreading of the polymer chain to improve its bridging effect. ${ }^{19,48}$

\subsection{Sludge floc size}

As reported previously, sludge floc size was regarded as an extensive and widely used index to evaluate the sludge flocculation performance..$^{33,49}$ The sludge floc with a large size usually performed well in separation and settlement, thus having an excellent flocculation performance. Therefore, the floc size distributions of the sludge conditioned by TPAD-U, CPAD, CPAM-1 and CPAM-2 at the optimum condition (dose: $40 \mathrm{mg}$
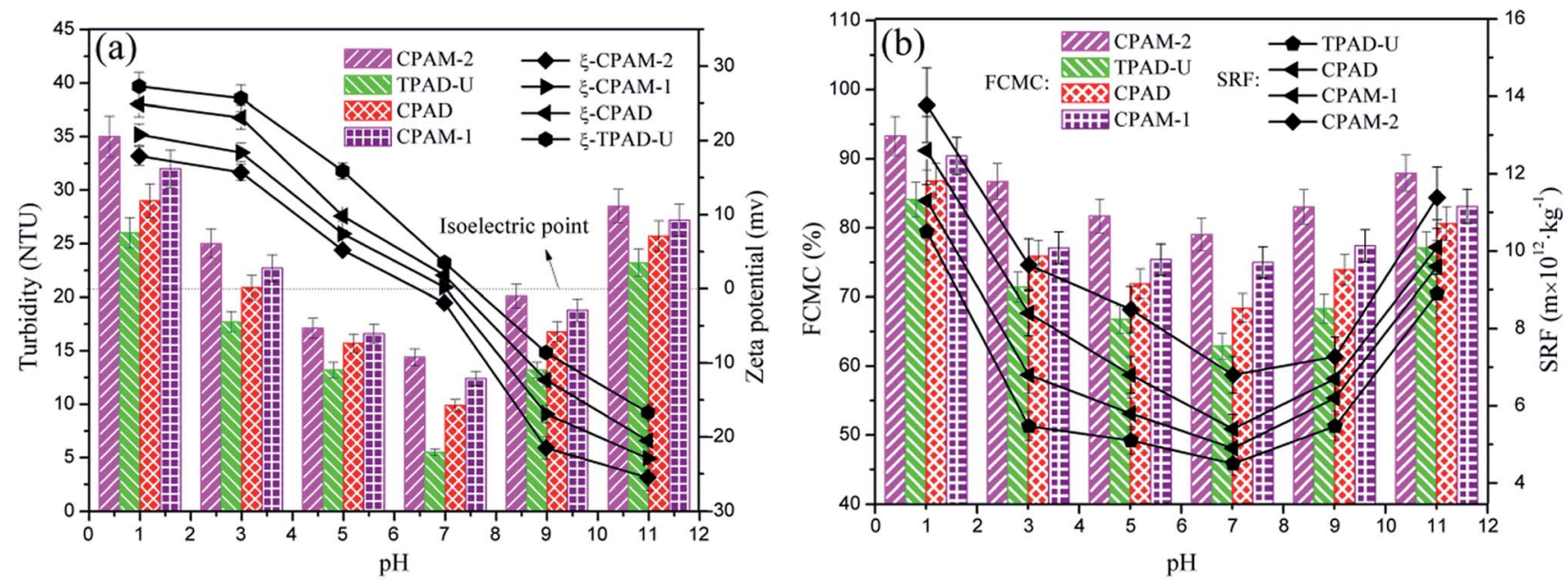

Fig. 10 Effect of the pH on (a) RT and zeta potential, (b) FCMC and SRF. 
$\mathrm{L}^{-1}, \mathrm{pH}:$ 7.0) were recorded, and the results were shown in Fig. 11 and Table 3 , where the $d_{10}$ represented $10 \%$ in the range $\left[0 \mu \mathrm{m}-d_{10}\right], d_{50}$ represented the median equivalent volumetric diameter, and $d_{90}$ represented $90 \%$ in the range $\left[0 \mu \mathrm{m}-d_{90}\right]$. The sludge floc size of TPAD-U was demonstrated the largest in the flocculants, and those were $229.931 \mu \mathrm{m}$ of $d_{10}, 562.428 \mu \mathrm{m}$ of $d_{50}, 1130.207 \mu \mathrm{m}$ of $d_{90}$, respectively. Meanwhile, it was found that the morphology of the sludge flocs conditioned by TPAD-U was more compact in ESI Fig. S2, $\uparrow$ compared with CPAD. The large and compact flocs was beneficial for the formation of drainage channel, and thereby a low SRF was obtained. By contrast, the small and loose floc would likely plug the channels and holes and result a big SRF, which was in consistent with the discussion in Section 4.1 and 4.2. These results all manifested that the cationic microblocks in TPAD-U contributed much to the excellent sludge flocculation behavior with the large and compact flocs via improving and strengthening the charge neutralization and bridging ability.
Table 3 The sludge flocs size distribution of $d_{10}, d_{50}$ and $d_{90}$ for flocculants

\begin{tabular}{lllr}
\hline Flocculant & $d_{10}{ }^{a}(\mu \mathrm{m})$ & $d_{50}(\mu \mathrm{m})$ & \multicolumn{1}{c}{$d_{90}(\mu \mathrm{m})$} \\
\hline TPAD-U & 229.931 & 562.428 & 1130.207 \\
CPAD & 195.396 & 470.622 & 858.349 \\
CPAM-1 & 143.832 & 358.052 & 770.832 \\
CPAM-2 & 123.004 & 313.347 & 609.930
\end{tabular}

${ }^{a} d_{10}: 10 \%$ in the range $\left[0 \mu \mathrm{m}-d_{10}\right] ; d_{50}: 50 \%$ in the range $\left[0 \mu \mathrm{m}-d_{50}\right]$; and $d_{90}: 90 \%$ in the range $\left[0 \mu \mathrm{m}-d_{90}\right]$.

\subsection{Flocculation mechanism}

According to the analytical results of flocculation tests, the flocculation mechanism involved in the flocculation process was discussed and shown in Fig. 12. The cationic microblock structure in TPAD-U played a vital role in improving the sludge flocculation performance. Specifically, the flocculation mechanism
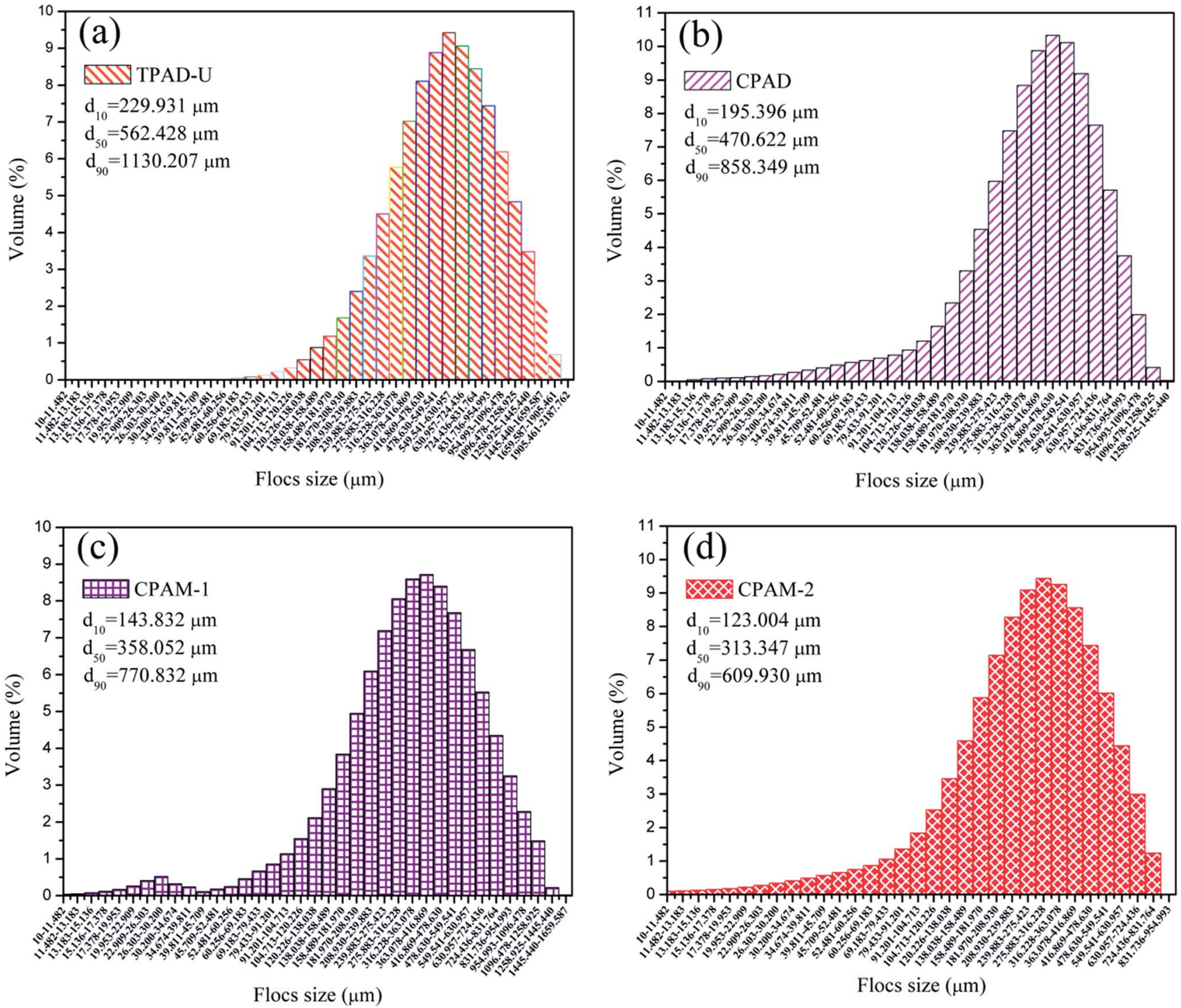

Fig. 11 Sludge flocs size distribution for (a) TPAD-U, (b) CPAD, (c) CPAM-1 and (d) CPAM-2. 


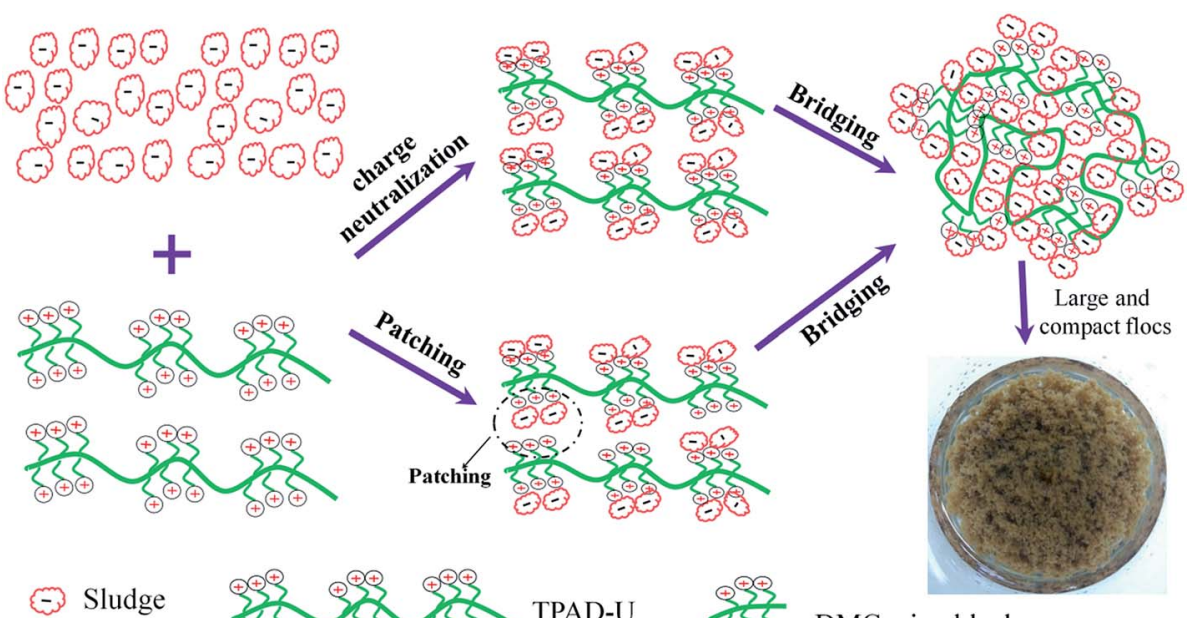

Fig. 12 Flocculation mechanism for TPAD-U.

related with the cationic microblock structure was summarized as follows: (1) the cationic microblocks in TPAD-U could greatly enhance the charge neutralization ability of the flocculant, and more negative charged sludge particles were neutralized completely and destabilized; (2) the ability of patching was also enhanced by the novel cationic microblock structure in TPAD-U, and which was helpful for the neutralization of negative charged sludge particles; ${ }^{18,19,37}$ and (3) the cationic microblocks had a strong electrostatic repulsion between the polymer chain, which was helpful for the polymer chain extension to improve bridging. Finally, the destabilized sludge particles were captured and anchored on the polymer chain to aggregate and form large and compact flocs.

\section{Conclusion}

A new flocculant (TPAD-U) with the cationic microblock structure was successfully prepared through ultrasonic-template polymerization technique. The microblock structure was confirmed by characterizations such as FT-IR, ${ }^{1} \mathrm{H}\left({ }^{13} \mathrm{C}\right) \mathrm{NMR}$, SEM and TGA. Meanwhile, the (I) ZIP mechanism of the ultrasonic-template copolymerization was demonstrated by a high association constant $\left(K_{\mathrm{M}}\right)$ value of 12.26 , which also indicated that the formation of the DMC microblocks. The reaction kinetics manifested that (1) the conversion and $R_{\mathrm{p}}$ were extremely effected by the $\mathrm{pH}$, and the optimal range of $\mathrm{pH}$ was from 4 to 6 ; (2) the free radical polymerization reaction was reflected by the power value (1.698) of $C_{\mathrm{M}}$ in the relationship of $R_{\mathrm{p}} \propto \mathrm{C}_{\mathrm{M}}^{1.698}$, which was caused by the product precipitation in the copolymerization process; and (3) the variation trend of conversion and $R_{\mathrm{p}}$ as a function of $n_{\mathrm{PMAA}}: n_{\mathrm{DMC}}$ was in line with the typical I (ZIP) template polymerization mechanism. Finally, the cationic microblocks in the TPAD-U significantly enhanced and improved the charge neutralization ability and further bridging, and thus improving the flocculation performance. The sludge flocculation results manifested that this enhanced charge neutralization and bridging effect of microblocky flocculant contributed much to lower value of SRF, FCMC and RT, larger size, and denser floc structure, compared with the other three flocculants (CPAD, CPAM-1 and CPAM-2).

\section{Acknowledgements}

This research was supported by the National Natural Science Foundation of China (Project No. 21677020 and 21477010).

\section{References}

1 H. P. Yuan, X. F. Yan, C. F. Yang and N. W. Zhu, Enhancement of waste activated sludge dewaterability by electro-chemical pretreatment, J. Hazard. Mater., 2011, 187, 82-88.

2 B. Tang and Z. Zhang, Essence of disposing the excess sludge and optimizing the operation of wastewater treatment: rheological behavior and microbial ecosystem, Chemosphere, 2014, 105, 1-13.

3 D. Mowla, H. N. Tran and D. G. Allen, A review of the properties of biosludge and its relevance to enhanced dewatering processes, Biomass Bioenergy, 2013, 58, 365-378.

4 J. Olivier, J. B. Conrardy, A. Mahmoud and J. Vaxelaire, Electro-dewatering of wastewater sludge: an investigation of the relationship between filtrate flow rate and electric current, Water Res., 2015, 82, 66-77.

5 D. Y. Chen and J. Yang, Effects of explosive explosion shockwave pretreatment on sludge dewaterability, Bioresour. Technol., 2012, 119, 35-40.

6 G. Y. Zhen, X. Q. Lu, B. Y. Wang, Y. C. Zhao, X. L. Chai, D. J. Niu, A. H. Zhao, Y. Y. Li, Y. Song and X. Y. Cao, Synergetic pretreatment of waste activated sludge by $\mathrm{Fe}(\mathrm{II})-$ activated persulfate oxidation under mild temperature for enhanced dewaterability, Bioresour. Technol., 2012, 124, 2936.

7 H. Zhang, J. K. Yang, W. B. Yu, S. Luo, L. Peng, X. X. Shen, Y. F. Shi, S. N. Zhang, J. Song, N. Ye, Y. Li, C. Z. Yang and S. Liang, Mechanism of red mud combined with Fenton's 
reagent in sewage sludge conditioning, Water Res., 2014, 59, 239-247.

8 M. L. Christensen, K. Keiding, P. H. Nielsen and M. K. Jørgensen, Dewatering in biological wastewater treatment: a review, Water Res., 2015, 82, 14-24.

9 N. N. Duan, B. Dong, B. Wu and X. H. Dai, High-solid anaerobic digestion of sewage sludge under mesophilic conditions: feasibility study, Bioresour. Technol., 2012, 104, 150-156.

10 H. P. Yuan, N. W. Zhu and L. J. Song, Conditioning of sewage sludge with electrolysis: effectiveness and optimizing study to improve dewaterability, Bioresour. Technol., 2010, 101, 4285-4290.

$11 \mathrm{X}$. H. Zhang, H. Y. Lei, K. Chen, Z. Liu, H. Wu and H. Y. Liang, Effect of potassium ferrate $\left(\mathrm{K}_{2} \mathrm{FeO}_{4}\right)$ on sludge dewaterability under different $\mathrm{pH}$ conditions, Chem. Eng. J., 2012, 210, 467-474.

12 S. J. Skinner, L. J. Studer, D. R. Dixon, P. Hillis, C. A. Rees, R. C. Wall, R. G. Cavalida, S. P. Usher, A. D. Stickland and P. J. Scales, Quantification of wastewater sludge dewatering, Water Res., 2015, 82, 2-13.

13 M. Q. Niu, W. J. Zhang, D. S. Wang, Y. Chen and R. L. Chen, Correlation of physicochemical properties and sludge dewaterability under chemical conditioning using inorganic coagulants, Bioresour. Technol., 2013, 144, 337343.

14 W. J. Zhang, B. D. Cao, D. S. Wang, T. Ma, H. Xia and D. $\mathrm{H}$. Yu, Influence of wastewater sludge treatment using combined peroxyacetic acid oxidation and inorganic coagulants re-flocculation on characteristics of extracellular polymeric substances (EPS), Water Res., 2016, 88, 728-739.

15 W. J. Zhang, P. Xiao, Y. Y. Liu, S. W. Xu, F. Xiao, D. S. Wang and C. W. K. Chow, Understanding the impact of chemical conditioning with inorganic polymer flocculants on soluble extracellular polymeric substances in relation to the sludge dewaterability, Sep. Purif. Technol., 2014, 132, 430-437.

16 K. E. Lee, N. Morad, T. T. Teng and B. T. Poh, Development, characterization and the application of hybrid materials in coagulation/flocculation of wastewater: a review, Chem. Eng. J., 2012, 203, 370-386.

17 Z. L. Yang, B. Y. Gao, C. X. Li, Q. Y. Yue and B. Liu, Synthesis and characterization of hydrophobically associating cationic polyacrylamide, Chem. Eng. J., 2010, 161, 27-33.

18 Q. Q. Guan, H. L. Zheng, J. Zhai, C. Zhao, X. K. Zheng, X. M. Tang, W. Chen and Y. J. Sun, Effect of Template on Structure and Properties of Cationic Polyacrylamide: Characterization and Mechanism, Ind. Eng. Chem. Res., 2014, 53, 5624-5635.

19 Z. A. Zhang, H. L. Zheng, F. Huang, X. Li, S. Y. He and C. Zhao, Template Polymerization of a Novel Cationic Polyacrylamide: Sequence Distribution, Characterization, and Flocculation Performance, Ind. Eng. Chem. Res., 2016, 55, 9819-9828.

20 Y. X. Zhang, F. P. Wu, M. Z. Li and E. J. Wang, Novel Approach to Synthesizing Hydrophobically Associating Copolymer Using Template Copolymerization: The
Synthesis and Behaviors of Acrylamide and 4-( $\omega$ Propenoyloxyethoxy) Benzoic Acid Copolymer, J. Phys. Chem. B, 2005, 109, 22250-22255.

21 F. Israr, D. Y. Chun, Y. M. Kim and D. K. Kim, High yield synthesis of Ni-BTC metal-organic framework with ultrasonic irradiation: role of polar aprotic DMF solvent, Ultrason. Sonochem., 2016, 31, 93-101.

22 C. X. Peng, B. D. Chen, Y. Qin, S. H. Yang, C. Z. Li, Y. H. Zuo, S. Y. Liu and J. H. Yang, Facile Ultrasonic Synthesis of CoO Quantum Dot/Graphene Nanosheet Composites with High Lithium Storage Capacity, ACS Nano, 2012, 6, 1074-1081.

23 O. Ayyildiz, S. Sanik and B. Ileri, Effect of ultrasonic pretreatment on chlorine dioxide disinfection efficiency, Ultrason. Sonochem., 2011, 18, 683-688.

24 M. Zheng, Y. C. Liu, J. X., H. Zuo, C. W. Wang and W. M. Wu, Ultrasonic Treatment Enhanced Ammonia-Oxidizing Bacterial (AOB) Activity for Nitritation Process, Environ. Sci. Technol., 2016, 50, 864-871.

25 X. F. Cui, J. W. Talley, G. J. Liu and S. L. Larson, Effects of primary sludge particulate (PSP) entrapment on ultrasonic (20 kHz) disinfection of Escherichia coli, Water Res., 2011, 45, 3300-3308.

26 D. Gopi, J. Indira, L. Kavitha, M. Sekar and U. K. Mudali, Synthesis of hydroxyapatite nanoparticles by a novel ultrasonic assisted with mixed hollow sphere template method, Spectrochim. Acta, Part A, 2012, 93, 131-134.

27 B. Y. Deng, H. Lu, L. Q. Li, A. H. Shi, Y. H. Kang and Q. X. Xu, Determination of the number of binding sites and binding constant between diltiazem hydrochloride and human serum albumin by ultrasonic microdialysis coupled with online capillary electrophoresis electrochemiluminescence, J. Chromatogr. A, 2010, 1217, 4753-4756.

$28 \mathrm{H}$. Ghanem, D. Zollinger, R. Lytton and N. Ghanem, Determining ASR characteristics using dilatometer method, Construct. Build. Mater., 2012, 36, 1008-1015.

29 M. Niu, W. J. Zhang, D. S. Wang, Y. Chen and R. L. Chen, Correlation of physicochemical properties and sludge dewaterability under chemical conditioning using inorganic coagulants, Bioresour. Technol., 2013, 144, 337-343.

$30 \mathrm{~S}$. Poøowiński, Template polymerisation and copolymerisation, Prog. Polym. Sci., 2002, 27, 537-577.

31 A. K. Tripathi, J. G. Tsavalas and D. C. Sundberg, Monte Carlo Simulations of Free Radical Polymerizations with Divinyl Cross-Linker: Pre- and Post-gel Simulations of Reaction Kinetics and Molecular Structure, Macromolecules, 2015, 48, 184-197.

32 Y. G. He, G. Li, F. G. Yang, X. Q. Yu, Y. J. Cui and F. X. Ren, Precipitation Polymerization of Acrylamide with Quaternary Ammonium Cationic Monomer in Potassium Carbonate Solution Initiated by Plasma, J. Appl. Polym. Sci., 2006, 104, 4060-4067.

33 H. L. Zheng, Y. J. Sun, J. S. Guo, F. T. Li, W. Fan, Y. Liao and Q. Q. Guan, Characterization and Evaluation of Dewatering Properties of PADB, a Highly Efficient Cationic Flocculant, Ind. Eng. Chem. Res., 2014, 53, 2572-2582.

34 Y. Liao, H. L. Zheng, L. Qian, Y. J. Sun, L. Dai and W. W. Xue, UV-Initiated Polymerization of Hydrophobically Associating 
Cationic Polyacrylamide Modified by a Surface-Active Monomer: A Comparative Study of Synthesis, Characterization, and Sludge Dewatering Performance, Ind. Eng. Chem. Res., 2014, 53, 11193-11203.

35 D. F. Wang, T. Q. Zhao, L. Q. Yan, Z. M. Mi, Q. Gu and Y. M. Zhang, Synthesis, characterization and evaluation of dewatering properties of chitosan-grafting DMDAAC flocculants, Int. J. Biol. Macromol., 2016, 92, 761-768.

36 Y. J. Sun, M. J. Ren, C. Y. Zhu, Y. H. Xu, H. L. Zheng, X. F. Xiao, H. F. Wu, T. Xia and Z. Y. You, UV-Initiated Graft Copolymerization of Cationic Chitosan-Based Flocculants for Treatment of Zinc PhosphateContaminated Wastewater, Ind. Eng. Chem. Res., 2016, 55, 10025-10035.

37 H. L. Zheng, J. Y. Ma, C. J. Zhu, Z. Zhang, L. W. Liu, Y. J. Sun and X. Tang, Synthesis of anion polyacrylamide under UV initiation and its application in removing dioctyl phthalate from water through flocculation process, Sep. Purif. Technol., 2014, 123, 35-44.

38 Z. Abdollahi, M. Frounchi and S. Dadbin, Synthesis, characterization and comparison of PAM, cationic PDMC and $\mathrm{P}(\mathrm{AM}$-co-DMC) based on solution polymerization, $J$. Ind. Eng. Chem., 2011, 17, 580-586.

39 C. L. Zhao, H. L. Zheng, L. Feng, Y. L. Wang, Y. Z. Liu, B. Z. Liu and B. Z. Djibrine, Improvement of Sludge Dewaterability by Ultrasound-Initiated Cationic Polyacrylamide with Microblock Structure: The Role of Surface-Active Monomers, Materials, 2017, 10, 282.

40 P. Sannigrahi, D. H. Kim, S. Jung and A. Ragauskas, Pseudolignin and pretreatment chemistry, Energy Environ. Sci., 2011, 4, 1306-1310.

41 J. Y. Ma, J. Shi, H. C. Ding, G. C. Zhu, K. Fu and X. Fu, Synthesis of cationic polyacrylamide by low-pressure UV initiation for turbidity water flocculation, Chem. Eng. J., 2017, 312, 20-29.

42 X. Li, H. L. Zheng, Y. L. Wang, Y. J. Sun, B. C. Xu and C. L. Zhao, Fabricating an enhanced sterilization chitosan-based flocculants: synthesis, characterization, evaluation of sterilization and flocculation, Chem. Eng. J., 2017, 319, 119-130.

43 S. H. Lv, T. Sun, Q. F. Zhou, J. J. Liu and H. D. Ding, Synthesis of starch-g-p(DMDAAC) using HRP initiation and the correlation of its structure and sludge dewaterability, Carbohydr. Polym., 2014, 103, 285-293.

44 J. Y. Liu, G. F. Zhao, C. Duan, Y. F. Xu, J. Zhao, T. Deng and G. R. Qian, Effective improvement of activated sludge dewaterability conditioning with seawater and brine, Chem. Eng. J., 2011, 168, 1112-1119.

45 Y. J. Sun, H. L. Zheng, J. Zhai, H. K. Teng, C. Zhao, C. L. Zhao and Y. Liao, Effects of Surfactants on the Improvement of Sludge Dewaterability Using Cationic Flocculants, PLoS One, 2014, 9, 10.

46 H. L. Zheng, Y. J. Sun, C. J. Zhu, J. S. Guo, C. Zhao, Y. Liao and Q. Q. Guan, UV-initiated polymerization of hydrophobically associating cationic flocculants: synthesis, characterization, and dewatering properties, Chem. Eng. J., 2013, 234, 318-326.

47 D. F. Wang, T. Q. Zhao, L. Q. Yan, Z. M. Mi, Q. Gu and Y. M. Zhang, Synthesis, characterization and evaluation of dewatering properties of chitosan-grafting DMDAAC flocculants, Int. J. Biol. Macromol., 2016, 92, 761-768.

48 B. Bolto and J. Gregory, Organic polyelectrolytes in water treatment, Water Res., 2007, 41, 2301-2324.

49 R. Mao, Y. Wang, B. Zhang, W. Y. Xu, M. Dong and B. Y. Gao, Impact of enhanced coagulation ways on flocs properties and membrane fouling:Increasing dosage and applying new composite coagulant, Desalination, 2013, 314, 161-168. 